\title{
ON THE FORMATION OF SNOW PENITENTES
}

\author{
By G. C. Amstutz \\ (Missouri School of Mines and Metallurgy, Rolla, Missouri)
}

\begin{abstract}
An attempt is made to throw some light on the physical processes in the development of penitentes as a result of new observations in Peru and a study of the literature. This paper offers a variety of approaches to the problem rather than any final view or theory, and is therefore mostly suggestive and intended to be a program for further, more detailed research.

Zusammenfassung. Anhand von neuen Beobachtungen von den Hochanden in Peru und auf Grund von Literaturstudien wird versucht neues Licht auf die physikalischen Einzelheiten der Bildung von Büsserschnee $\mathrm{zu}$ werfen. Es werden verschiedene Wege vorgezeichnet und neue Lösungsmethoden vorgeschlagen.
\end{abstract}

\section{INTRODUCTION}

In 1953 the author was engaged in geological exploration work in the Cuajone-Toquepala porphyry copper area of southern Peru and had the opportunity of visiting some of the volcanoes of this region. On the top and the flanks of one of these volcanoes, the Volcán Tutupaca, $5820 \mathrm{~m}$., abundant snow penitentes were observed. Since then the author has been searching for an adequate explanation of this peculiar erosion form of snow and ice-two similar sediments. The reading of Professor Eitel's paper ${ }^{\mathrm{I}}$ on "thermal emissivity of refractories" injected a new line of thought into the "supersaturated solution" of observations on snow penitentes and led to the precipitation of the following lines, which I feel move a small step forward toward the correct answer-or one correct answer.

To the great satisfaction of the present author, similar ideas have been found, after the drafting of this manuscript, expressed and ably illustrated by the French glaciologist Louis Lliboutry. ${ }^{2,} 3$ The fact that only very few snow penitentes have been described from Peru, ${ }^{4}$ Lliboutry's somewhat provocative opinion about geologists, ${ }^{5}$ and the attempt to move beyond Lliboutry's concept, are the reasons for publishing another paper on snow penitentes.

\section{The Environment of Formation}

Troll ${ }^{4}$ and Lliboutry ${ }^{2,3}$ have shown that the formation of snow penitentes is not a simple process based on one erosional factor but rather a phenomenon which is produced by various physical processes. They have also shown that this peculiar erosional form is not restricted to the tropics but occurs in every continent and every latitude. The fact that in the tropics and at high altitudes the more striking examples are found is simply due to the increased magnitude of the processes and agents involved, as well as to the coincidence of more than one of these processes. Even in our latitudes and climates we may observe snow penitentes. Good examples formed recently along Highway 66 in Missouri, after a heavy snowfall and a week of dry, cold, windy weather.

The problem of the formation of snow penitentes is, by the way, an excellent example among the numerous geological processes which, for a long time and by many text-books even to-day, are believed to be due to some simple, uniform, single "physical" or "chemical" process. We know to-day that many of these processes have a complicated history. To mention only two, granitic rocks can have a rather complex parentage, and exfoliation can be caused by various different processes. ${ }^{6,7}$

\section{The Actual Process of Formation}

The steps involved in the incipient formation of snow penitentes are as follows:

I. On a snow cover the sun causes melting, sublimation or both, starting at points of lower 
density. A snow field is never perfectly homogeneous.* Dust may, of course, increase the speed and the number and shape of the formation of furrows and hollows.

2. Once the incipient hollows are started, the complex process as described in more detail below takes place. The shape and number of snow penitentes and hollows depend much on the original nature of the uppermost snow cover. Here we may compare the process with that of crystallization from a melt or a solution: the type and number of nuclei-and probably in both cases also the speed of formation-influence the end product. It is the previous conditions and the actual course of the process which influence the final shape at any one time.

Changes during the growth of the penitentes (or rather the growth of the holes between them) may come from two sources:

(I) Changes of physical conditions acting on the snow from the outside, such as changes of humidity, insolation, wind velocity and direction, etc.

(2) Changes of the internal fabric of the snow. Much is known of these, particularly from the excellent work done by the research groups on the Weissfluhjoch in Switzerland and of the S.I.P.R.E. Laboratory in Wilmette, Illinois.

Man-made furrows in the snow may occasionally produce penitente-like shapes. Yet not every spike in the snow is a penitente. The morphology of the snow shown by Lliboutry ${ }^{2}$ in Fig. 6 looks more like windblown "Harst", a wind erosion form due mostly to mechanical erosion. It is most probable that many snow penitentes start on initial snow ripples. The formation and physics of snow ripples was described in detail by Bagnold. ${ }^{9} \mathrm{R}$. Moss observed snow barchans ${ }^{10}$ and the snow pictured by Lliboutry and also by Work and others ${ }^{\mathrm{II}}$ as small penitentes in a skifield or snow field, and called Harst by me, should be studied on the basis of Bagnold's discussion of the physics of wind blown sand and snow.

But there is another interesting feature which I have never found mentioned or described anywhere. Cross sections in snow sometimes exhibit stylolitic microtectonic structures. These can be caused by ski tracks or by natural diagenetic compaction. A detailed study of these features and a comparison with the corresponding phenomena in limestones, etc., should contribute considerably to the elimination of certain impossible epi-diagenetic ideas on stylolites.

Among the causes active during the progressive formation of penitentes the following can be listed as important.

(I) Captured reflection.

(2) Differential ablation or melting or both, from top of penitentes to bottom of furrows.

(3) Dust accumulations in hollows, causing faster melting with consequent evaporation.

(In some cases, however, dust and dirt form crests of more resistance. See, for example, the ablation polygons pictured by Richardson and Harper. ${ }^{12}$ )

The fact that snow penitentes are much more common in the tropics and at high elevations seems to suggest that captured light is the strongest cause. Factor (2) may be said to be of about the same magnitude in various latitudes, and factor (3) should be high close to cities or to active volcanoes, and so in rather irregularly distributed areas, with no relation to altitude or latitude.

Cause (I): The direct effect of insolation is probably by far the strongest factor during the formation of snow penitentes. This is suggested by various observations: $(a)$ the general increase of size in tropical zones and in areas of high elevation; $(b)$ the general east-west orientation of oval or fish-shaped penitentes; $(c)$ ice penitentes form also on glaciers where the vapor pressure on top of the penitentes is probably not different from that at the bottom.

Cause (2): Lliboutry ${ }^{2}$ mentions that the drier the air, the lower the dew point and the

* It is hard to visualize Lliboutry's statement ${ }^{8}$ that "By degrees successive furrows will appear, and from a few hollows a whole field of penitents will be formed". This is not a "chain reaction" like crystallization in a supersaturated solution. Every hole has to start "on its own". The only connection which might exist and lead to a certain periodicity is the wave nature of the wind flowing over the surface of the snow. 
lower the ablation. Because of this law we must assume, again with Lliboutry, that the "warmed up" hollows (see Cause (3)) produce vapor from melted and evaporated, or simply sublimed, ice or snow, whereas the colder tops with drier air and thus a lower dew point experience less erosion through melting and evaporation or through sublimation.

The question now arises whether we may assume conditions under which evaporation or sublimation takes place in the hollows, and precipitation by frosting occurs when the water vapor rises and passes over the tops of the penitentes. If we use Lliboutry's data $--5^{\circ} \mathrm{C}$. on top of a penitente and $+10^{\circ} \mathrm{C}$. in the adjacent valley-the probability certainly seems to exist. One also gets the impression that this might have happened to a moderate degree in some cases where overhanging shoulders or tops of penitentes are covered with solid ice which does not show any apparent layering. But abundant, consistent and accurate observations along this line are still lacking.

The fact that the grain size of the snow increases from bottom to top of a penitente-as observed and described by Lliboutry ${ }^{13}$-may have something to do with this process of evaporation and redeposition. If the grain size always increases in such a manner, we must find a cause for this metamorphism. Lliboutry ${ }^{14}$ ascribes it to the "grandes oscillations thermiques diurnes". It is more likely that this grain size distribution is due to the differences in temperature, humidity and ablation existing between the hollows and the tops of the penitentes, because the daily oscillations of temperature affect the whole penitente, whereas the conditions prevailing towards the top of a penitente obviously favor a re-crystallization of the snow. Consecutive observations made on a number of penitentes over a number of days or weeks are still lacking. Also Lliboutry does not state whether he compares snow grains of penitentes sampled at the same distance from the outside. He mentioned, however, an interesting relationship between the content of impurities in the snow and the degree of re-crystallization and complete melting. Yet much work remains to be done even along this line.

It is known that firn and ice are somewhat higher in $\mathrm{D}^{2}$ and $\mathrm{O}^{18}$ and the early melt waters are higher in $\mathrm{H}^{1}$ and $\mathrm{O}^{16}$. It would be interesting to see whether there is an enrichment to $\mathrm{D}^{2}$ and $\mathrm{O}^{18}$ in penitente formation, due to a difference in vapor pressure of $\mathrm{HDO}$ and $\mathrm{H}_{2} \mathrm{O}$ (see Rankama ${ }^{15}$ ). It is very likely that such an isotope fractionation takes place.

We may further assume that a slight breeze is constantly mixing the air and no significant difference in humidity exists, whereas the difference in absorption of radiation discussed in the following paragraphs is not changed by wind. To the knowledge of the writer the penitentes observed on Volcán Tutupaca (Figs. I, 2, 3, p. 309) formed almost exclusively under a constant slight breeze of changing direction. The same observation as reported by Lliboutry ${ }^{2}$ from the Paso de los Piuquenes (4030 m.) in Chile was made on Volcán Tutupaca on I October 1953: on the windy north-east side there was only an incipient small development of penitentes, whereas the large ones pictured in Figs. 1, 2, and 3 were formed on the warmer and protected south-east side.

Cause (3): There is not much to say about Cause (3), whereas Causes (I) and (2) will be discussed in a somewhat more detailed way than found in the literature on this subject. Cause (3) may be important in those cases where considerable dust accumulations are found in the hollows, or where thick dust, ash or moraine accumulations insulate the crests (see Richardson and Harper ${ }^{\text {II }}$ ).

To the author's knowledge, the possible consequences of differential wind ablation due to differences of velocity between tops and bottoms of penitentes have not been investigated either. A driver of a car knows that the ice on his wind shield often disappears if he accelerates to a higher velocity. Simple experiments in a wind tunnel would add much to the knowledge of the relationship between sublimation of ice and snow and the velocity of the wind.*

* In his Snow Structure and Ski Fields. London, Macmillan, 1936, Mr. G. Seligman devotes some pages to ice sublimation and gives some quantitative details together with photomicrographs of the evaporation of firn by wind. G.C.A. 
The Theory of Thermal Absorption in Holes

Cause (3) is actually the reverse of the theory of thermal emission from an irregular or porous surface. This relation is what struck me when reading Eitel's paper on thermal emissivity, ${ }^{\mathbf{I}}$ and the theory of thermal absorption developed here is but a reversal of the theory of thermal emissivity.

The following two empirical rules are well known to practising engineers, particularly to metallurgists and heat engineers:

(I) The rougher the surface, the higher is the heat emissivity.

(2) The rougher the surface, the higher also is the heat absorption.

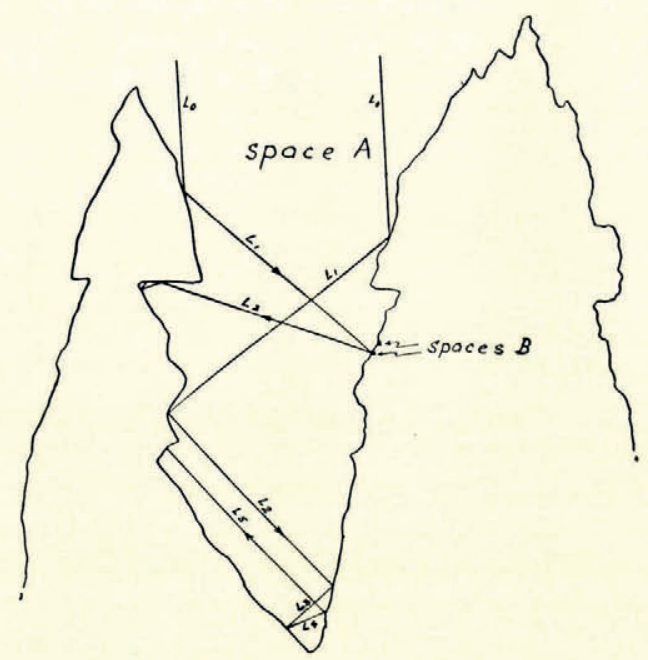

Fig. 4. Cross section through two snow penitentes showing the reflection and capture of light in space element $A$ and $B$. The size of the penitentes may vary anywhere from $I \mathrm{~mm}$. (in which case space $A$ is only a few times the size of space $B$ ) to $3 \mathrm{~m}$.

These facts are the so-called black body laws of physics. Lliboutry ${ }^{2}$ mentions this on p. 332. Yet there are numerous details of them which, to my knowledge, have never been discussed by physicists or geologists. These details must be understood and should be studied before any new theory of snow penitente formation enters our text-books.

First we have to differentiate geometrically between two scales of "black body condition" in snow penitentes. The first geometric locus is circumscribed by the walls of two or more neighboring snow penitentes and the bottom of the valley between them. We can call this space $A$. The second geometric locus is described by the walls of the pores in the snow or ice of the penitentes and the furrows in between. These pores are circumscribed by snow or ice crystals which are of different size and fabric. This space we will call $B$. Naturally, the various $A$ 's, $A_{1}, A_{2}, A_{3}, \ldots$ and the various $B$ 's, $B_{1}, B_{2}, B_{3}, \ldots$ often communicate with each other to a greater or lesser extent, i.e. the macroscopic and the microscopic fabrics of the penitentes are more or less porous.

When following the process of thermal radiation closely, we can break it down into that captured by multi-reflection and multi-absorption in the primary, macro-space $A$ and in that captured in the secondary, micro-space $B$. It goes without mentioning that the thermal energy produced originates from that portion of the incoming light which is absorbed. Thus, if we follow a light beam $L$ hitting a wall of a snow penitente in Fig. 4 , we see that logically the thermal effect is a direct function of the amount of light entering upon a space unit on the 
wall or the bottom of snow penitentes or their furrows. This is a first contribution to our final equation. The formation of snow penitentes $F_{p}$ is a function of the number of times a sunbeam is reflected, and the amount of light falling onto unit area, and thus a function of the geometry $G$ of the valley. We see here, as a partial result of our discussion, that we are dealing with some sort of vicious circle: the deeper the furrows or valleys, the more often is the light reflected, and the faster will the development, the "erosion" of the valley, proceed. At the same time we return to our fundamental "law": the rougher the surface, the higher is the heat absorption.

Yet there is still another "vicious circle" which again is only one of the factors causing erosion of snow penitentes: the deeper down the furrows, the more often are beams reflected per $\mathrm{cm} .^{2}$ of surface, the higher should be the actual thermal absorption. However, as mentioned, the light loses with every reflection some of its energy so that much of this increased density of reflection is counter-balanced by the lower energy of the light: $L_{0}>L_{\mathrm{I}}>L_{2}>L_{3}$. Yet the amount of light reflected normally decreases from top to bottom because the top is colder and usually (but not always) consists of ice while the bottom portions are porous and softer.

The basic discussion of the light path in the primitive space $B$, the "micro-space", is principally the same as the discussion of reflection in $A$.

What becomes evident now is the strong influence of the nature of $B$ in different layers from top to bottom of $A$ on the light path of $L$ in $A$. If much light is absorbed in upper layers, i.e. at the first reflection points of $L$, thus, if

$$
L_{\mathrm{o}} \gg L_{\mathrm{r}} \gg L_{2} \gg L_{3} \ldots \text {, }
$$

we can expect the valleys to be flatter than under the condition $L_{0}>L_{1}>L_{2}>L_{3} \ldots$, where the valleys should be deeper.

It should be taken into account, furthermore, that the spectral composition $\lambda$ of the light changes with every reflection. Thus:

$$
\lambda_{0} \neq \lambda_{1} \neq \lambda_{2} \neq \lambda_{3} \ldots \text {. }
$$

This should be investigated and taken into account. Also, from a certain point below the top of penitentes, reflection becomes more complicated because often some of the reflection takes place on the water film which forms on melting, whereas some reflects on the solid surface only. The absorption and reflection of water is different from that of ice crystals, and so is the heat conductivity.

Returning to a more detailed discussion of the space element $B$, we see that another group of factors is very important. These are the quantity of radiation reflected (albedo) on the outer and inner surfaces, the quantity of radiation absorbed by a particular space element, and also the amount of ice or snow present in this space element. On the one hand ice is generally transparent whereas snow is only translucent. We may therefore assume that whatever light enters ice or snow, it is less absorbed in ice than in snow. Yet on the other hand the albedo of snow is generally higher than that of ice, so that less light enters snow in the first place. This effect thus acts in the opposite direction to the previous one and is probably the reason for the fact that snow is more resistant to melting than clear ice when occurring on the surface of a glacier, where the reflected light is lost.

In between snow penitentes this radiation is not lost but rather trapped, and the question arises whether this change of conditions has anything to do with the fact that between snow penitentes icy layers seem to be more resistant than snow layers. As shown above, other factors have also to be taken into account and we should be careful not to over-emphasize the effects of radiation. The differences of ablation between the different strata of snow and ice in snow penitentes may also be caused by simple melting due to the heating of the spaces between the penitentes. Lliboutry measured, as mentioned above, temperatures up to $10^{\circ} \mathrm{C}$. in valleys between penitentes. Wind action may also contribute its share, and both simple melting and 

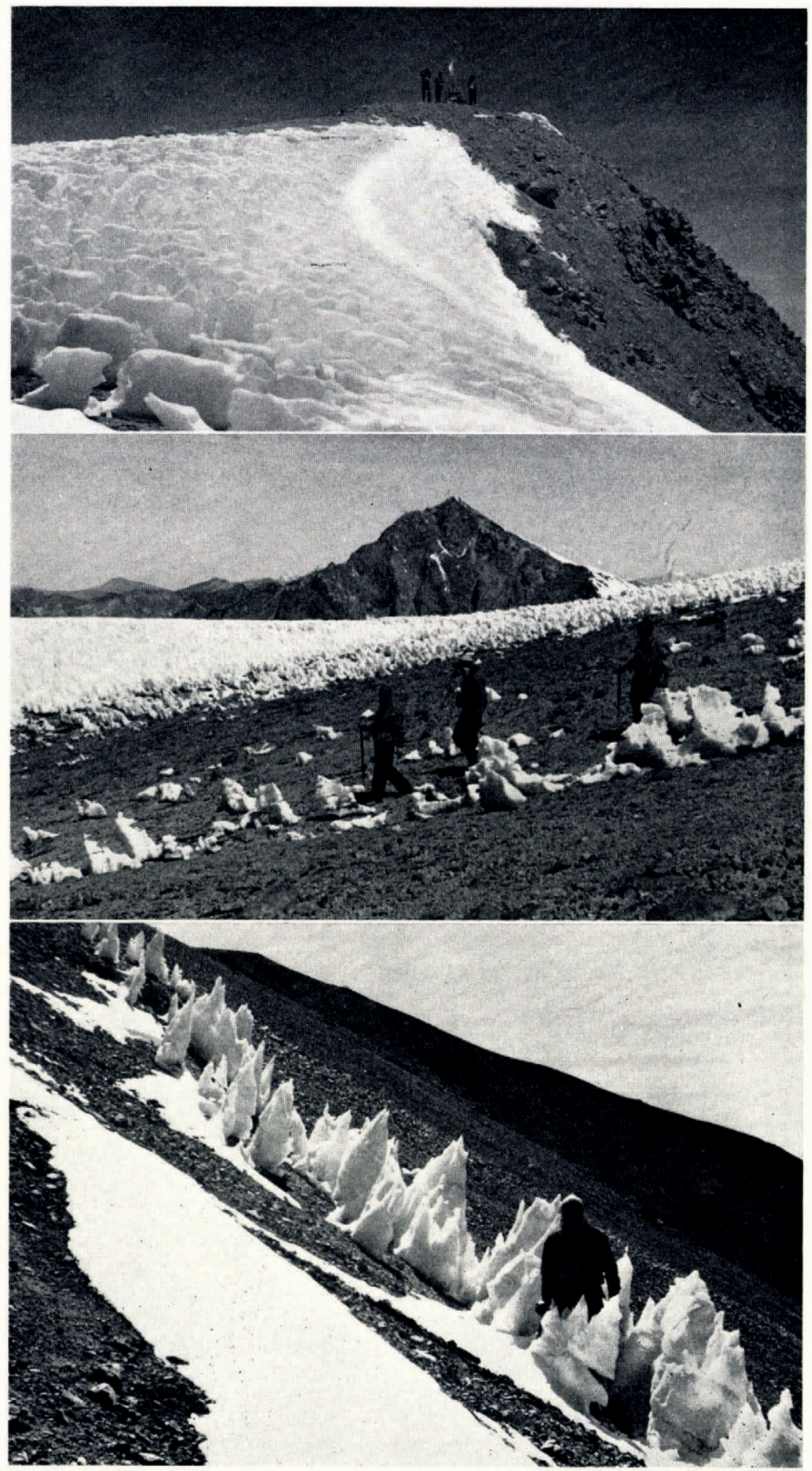

Fig. I. Snow penitentes striking approximately east-west, on top of Volcán Tutupaca, Southern Peru. Lee side of mountain (south-east side). Elevation $5820 \mathrm{~m}$. Photograph taken on 1 October 1953.

Fig. 2. Field of snow penitentes on the shoulder just below the top of Volcan Tutupaca, Southern Peru, at an elevation of about $5800 \mathrm{~m}$. Looking south, toward the smoking southern peak of Tutupaca

Fig. 3. Snow penitentes on the east slope of Volcan Tutupaca, Southern Peru, at an elevation of about $5700 \mathrm{~m}$. As in Figs. I and 2, the strike of the penitentes is about east-west. The layering is clearly visible and is parallel to the slope. A recent snowefall has partly filled the spaces between the individual penitentes. The two types of thermal absorption effects are clearly visible from the geometry of the penitentes. All penitentes are seasonal or periodic and not perennial (see Troll4, fo 27 and $p .70$ ). The fact that the volcano Tutupaca is usually covered with heavy snow throughout the rainy season 


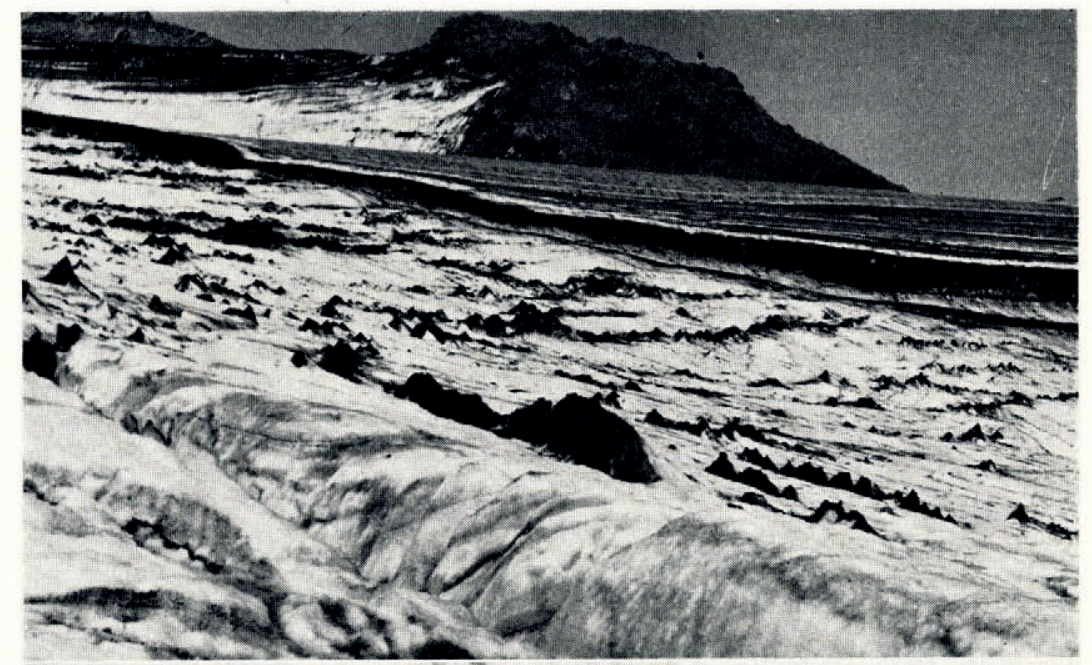

Fig. I (top). Lines of dirt cones on the upper Whakapapa Glacier. In the background melt borders of volcanic ash Fig. 3 (centre left). Dirt cones along a crevasse. The ash cover is $5-7 \mathrm{~cm}$. thick. Pinnacle ridge in background

Fig. 4 (centre right). Hummocky surface on the upper Whakapapa Glacier. The hummocks developed later into isolated dirt cones

Fig. 6 (bottom left). Lines of submerged dirt cones, Whakapapa Glacier. In the foreground centre and right the top of some dirt cones are still visible. Melt borders of volcanic ash are visible in the background

Fig. 7 (bottom right). Large ice cone on the saddle of the North Crater, Ruapehu. The cone has been tilted towards the interior of the crater. The thin black lines indicate annual dirt strata. The thick lines represent ash layers of volcanic eruptions from Ruapehu or Ngauruhoe
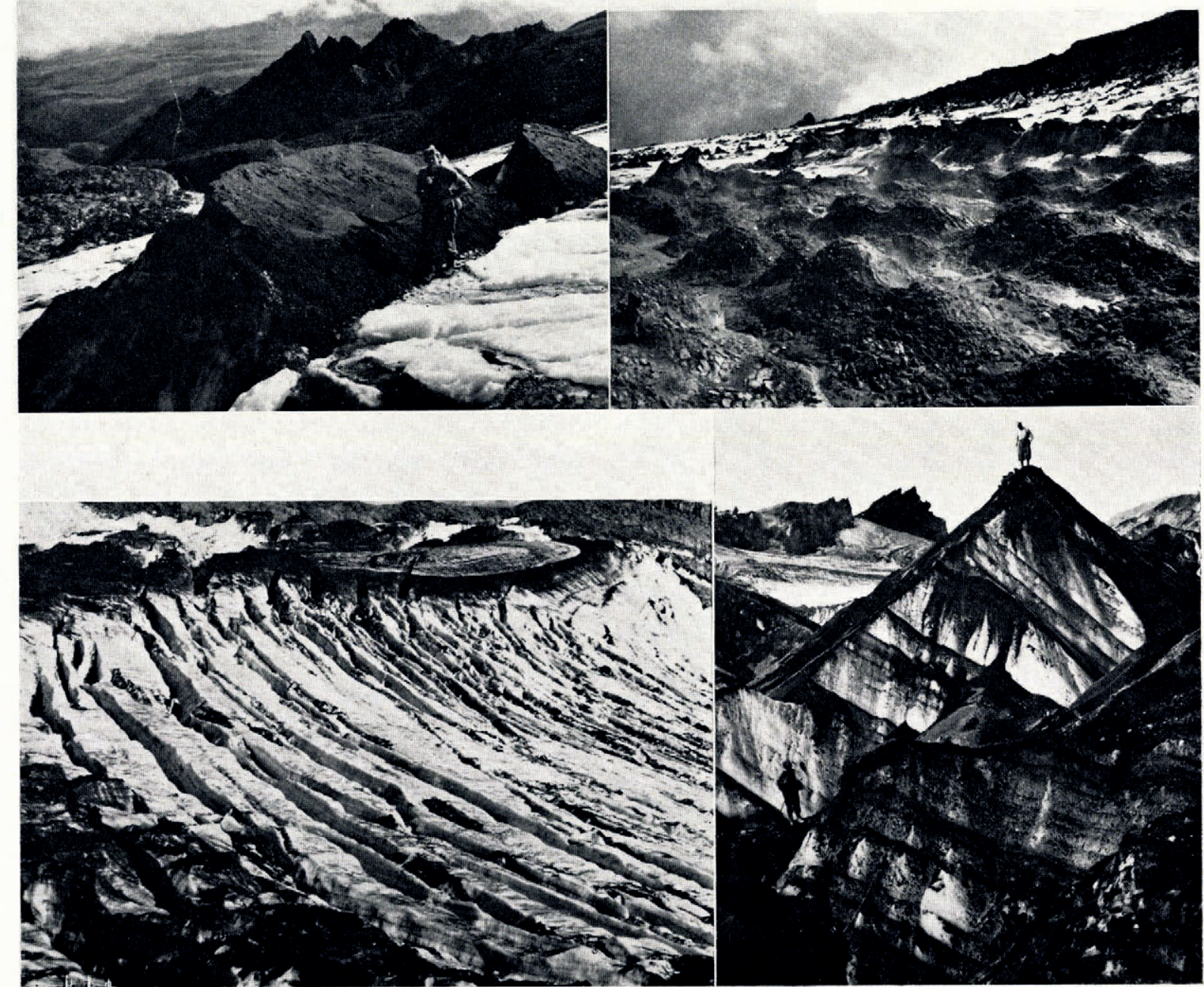
wind action will of course act in proportion to the exposed surface, which is greatest in snow and smallest in solid ice. We need more measurements and observations of many kinds, especially with regard to the absorption factors of ice, snow, and water, particularly for ultra-violet radiation at high altitudes; an excellent review of our present knowledge of the radiation properties of ice has been produced by S.I.P.R.E. ${ }^{16}$

On the other hand, we have to consider also the actual amount of frozen water present in a cubic centimetre of ice and in a cubic centimetre of snow. Generally we are under the impression that a snow layer melts away much faster than icicles from the roof of a house. We forget, however, that the amount of frozen water in a cubic centimetre of an icicle is generally much higher than in snow. This has, to my knowledge, never been taken into consideration in discussion of snow penitentes. It is, though, a simple principle and well illustrated by Fig. 3 of this paper, where the icy and/or translucent portions or layers of penitentes act like resistant sedimentary beds in erosion.

A careful study of the physical reasons for penitente morphology has also to consider the optical geometry of the side walls of penitentes. For example, it is obvious that concave forms which are fairly abundant, serve as focusing mirrors. If the light concentrated by such curved surfaces hits the adjacent penitentes it will cause strong heat concentrations.

This article shows that the formation of snow penitentes is a complex process involving many factors. Among these radiation may produce the strongest effects. Many more observations are needed and much research remains to be done.

MS. received 18 March $195^{8}$

\section{REFERENGES}

I. Eitel, W. Thermal emissivity of refractories and its importance for glass furnace operation. Glass Industry, Vol. 36, 1955, p. 193-97, 228.

2. Lliboutry, L. The origin of penitents. Fournal of Glaciology, Vol. 2, No. 15, 1954, p. 331-38.

3. - La structure des penitents de neige. Union Géodésique et Geophysique Internationale. Association Internationale d'Hydrologie Scientifique, Assemblée Générale de Rome, 1954, Tom. 4, [1956], p. I I 7-22.

4. Troll, C. Büsserschnee in den Hochgebirgen der Erde. Petermanns Geographische Mitteilungen. Ergänzungsheft 240, 1942, I03 p. particularly p. 64-70.

5. Lliboutry, L. op. cit., 1954, p. 331.

6. Amstutz, G. C. "Granitisation" und Erzlagerstätten. Neues Jahrbuch für Mineralogie. Monatshefte, Vol. I, I957, p. I-12.

7. The theory of spheroidal weathering and exfoliation. [In press, 1958.]

8. Lliboutry, L. op. cit., I 954 , p. 336 .

9. Bagnold, R. A. The physics of blown sand and desert dunes. London, Methuen, I94I. p. I44-66.

Io. - op. cit. p. 22 I.

I I. Work, R. A., and others. Discussion of "Report of the Committee on Snow, 1954-55". Transactions. American Geophysical Union, Vol. 38, No. I, 1957, p. 114-15.

12. Richardson, W. E., and Harper, R. D. M. Ablation polygons on snow-further observations and theories. Fournal of Glaciology, Vol. 3, No. 21, 1957, p. 25-27.

13. Lliboutry, L. op. cit. [1956], p. 121.

14. - op. cit. [1956], p. 122 .

15. Rankama, K. Isotope geology. New York, I954. p. 155-244.

16. Mantis, H. T. (ed.) Review of the properties of snow and ice. $S[$ now $] I[$ ce and $] P[$ ermafrost $] R$ [esearch $] E[$ stablishment] Report 4, 1951 p. 60-72. 